\title{
STUDYING SELECTION CRITERIA AND GENETIC VARIABILITY FOR IMPROVEMENT OF INDIGENOUS MAIZE IN PAKISTAN
}

\author{
Muhammad Amir Maqbool ${ }^{1,2}$, Muhammad Aslam ${ }^{1, *}$, Abdurahman Beshir ${ }^{3}$, Muhammad Sarwar \\ Khan $^{4}$ and Muhammad Tariq Saeed ${ }^{1}$
}

\author{
${ }^{1}$ Department of Plant Breeding and Genetics, University of Agriculture Faisalabad, Pakistan; ${ }^{2}$ Currently at \\ International Maize and Wheat Improvement Center (CIMMYT), Pakistan; ${ }^{3}$ International Maize and Wheat \\ Improvement Center (CIMMYT), South Asia Regional Office, Khatmandu, Nepal; ${ }^{4}$ Centre of Agricultural \\ Biochemistry and Biotechnology (CABB), University of Agriculture Faisalabad, Pakistan. \\ "Corresponding author's e-mail: aslampbg@gmail.com
}

\begin{abstract}
Maize (Zea mays L.) is short duration, high yielding crop, and it can be grown in both spring and kharif seasons in Pakistan. In current study white and yellow maize germplasms were compared for correlations and genetic variability based on different agronomic traits to define selection criteria for maize improvement. Significant differences were observed for yield and related components for entries, checks, all tested genotypes, yellow and white germplasm. Yellow maize genotypes showed higher yield potential compared to white maize genotypes because of more grains per row and number of rows per cob. Based on correlation and path coefficient analysis, yield per plant was proved as appropriate selection criteria for white maize whereas, yield per plant and grains per row were suitable selection criteria for genetic improvement of yellow maize. Total carotenoid contents of yellow maize were independent of the yield so, both can be simultaneously targeted for genetic improvement without paying yield penalty. However, further dissection of genetic variability in yellow maize germplasm based on provitamin A carotenoids is prerequisite. So, far as genotypes, 19189, 15159, 19201, 15018, 15216, 15170, 15155, 19196, 15318 and 19174 among white maize germplasm whereas, 14965, 14982, 19205, 15019, 14971, 15163, 15205, 24687, 15207 and 15194 among yellow maize germplasm were the potential high yielding genotypes. Findings of the study in terms of selection criteria and potential maize genotypes could be useful in different breeding programs for genetic improvement of maize.
\end{abstract}

Keywords: Yellow \& white maize, genetic variability, augmented design, correlation coefficients, total carotenoid contents.

\section{INTRODUCTION}

Maize is indigenous to western hemisphere, originating in Mexico. Almost 300 different races of maize are reported from Mexico, Caribbean and South \& Central America. After discovery, maize quickly moved from center of origin to Europe, Africa and Asia (Brown et al., 1985). Asian origin of the maize is reported from the foothills of the Himalayas (Dhawan, 1964). This primitive type of maize is called as Sikkim Primitive 1 and Sikkim Primitive 2. These are also known as living fossils of ancient maize (Dhawan, 1964). Maize is subjected to exclusive evolutionary changes and adapted to the wide range of territories. Large number of biotypes evolved which can be grown from sea level to 12,000 feet altitude, from tropics to the North Temperate Zone, and extending growing periods from 6 weeks to 13 months (Brown et al., 1985).

White and yellow maize are two commonly grown phenotypes. Recently it is observed that white maize is being replaced with yellow maize in different parts of the world, due to higher associated profitability with yellow maize (Mejia and Peel, 2009). It is reported that higher productivity of yellow maize is associated with higher responses to input applications like, fertilizers and irrigation water (Mejia and Peel, 2009). Demand for yellow maize increased many folds because of its uses for human food, bioenergy, biofortification and animal feed. White corn has pure white kernel which is dry milled to make flour. White corn is also used for starch, paper production and making snack foods. Relative consumption of white and yellow maize is dependent on several factors like market price, nutritional importance and traditional norms. Nutritional importance is the key factor which can alter the consumer's preferences (Muzhingi et al., 2008).

Asian countries like China, India, Pakistan, Indonesia, Nepal, Thailand, Philippine and Vietnam are collectively producing the $98 \%$ of Asian maize and 26\% of global maize (Erenstein, 2010). Area, production and yield of maize are continuously increasing in the Asian countries (Abbas et al., 2017; Zulfiqar et al., 2017). Per annum growth in area, yield and production of maize in Pakistan is 1.5, 2.2 and 3.7\%, respectively since 1968 which is one of the highest among Asian countries (USDA-FAS, 2008). In Pakistan, maize is ranked at top as cereal and grown twice a year i.e. spring and kharif. The area under maize cultivation is increasing in the country due to shorter crop duration, two cropping seasons per year, higher 
market price, high net revenue, high indigenous consumption and high industrial demand compared to other cereal crops. Still there is huge gap in potential yield compared to maize yield in developing countries, which could be filled through genetic manipulations. Genetic improvements attained in the tropical and subtropical maize germplasm are extensively lower than temperate regions (Badu-Apraku et al., 2010, 2011). Therefore for improving the maize genotypes for higher potential and increasing the variety turnover, repeated selections in maize germplasm for genetic improvement in topics and subtropics is required. So, exploration of local maize germplasm for estimation of yield potential, selection criteria and potential candidate genotypes is important to provide first-hand information for establishment of strong maize breeding program in the country.

\section{MATERIALS AND METHODS}

Maize germplasm used in current study was collected from Plant Genetic Resource Institutes (PGRI), National Agricultural Research Center (NARC), Islamabad, Pakistan. PGRI collected this germplasm across the country including; Balochistan (Kalat, Ziarat, Sibi, Qila Abdullah, Pishin, Chagai, Qila Saifullah, Loralai, Quetta, Mastung, Panjgur), Punjab (Narowal, Bahawalpur, Rawalpindi, Sheikhupura, Gujranwala, Sialkot, Attock, Faisalabad, Khushab, Muzaffargarh, Okara, Sahiwal), Khyber Pakhtunkhwa (Malakand, Swat, Mansehra, Parachinar, Kohat, Hangu, Dir, Chitral, Batgram, Haripur, Abbotabad), Azad Jammu \& Kashmir (Rawalakot, Muzaffarabad, Punch, Bagh, Kotli) and Gilgit-Baltistan. Germplasm comprised of 350 genotypes including white and yellow maize accessions.

Experimental conditions: The present study was conducted in research area of Department of Plant Breeding and Genetics, University of Agriculture Faisalabad, Punjab, Pakistan during Autumn-2015 (30-July-2015 to 26November-2015) by following augmented layout design. The layout for field was generated using CIMMYT-FIELDBOOK Software. Experimental site was situated at latitude of $31.43^{\circ} \mathrm{N}$, longitude of $73.1^{\circ} \mathrm{E}$, and elevation is $184.5 \mathrm{~m}$ from sea level. Meteorological conditions of the subjected season were given in Figure 1. Four commercially grown maize genotypes were used as local checks which were repeated seven times whereas; all other subjected genotypes were sown without repetition. Sowing was done on $4 \mathrm{~m}$ long rows which were $75 \mathrm{~cm}$ apart from the adjacent rows and plant to plant distance was $20 \mathrm{~cm}$. Sowing was done manually on the ridges after irrigation. All the standard management practices were followed from sowing to harvesting of crop.

Data collection: Data were collected for days to $50 \%$ silking (DS), days to 50\% tasseling (DT), anthesis silking interval (ASI), plant height $(\mathrm{cm} ; \mathrm{PH})$, ear height $(\mathrm{cm} ; \mathrm{EH})$, root lodging (RL), stem lodging (SL), grains per row (GPR), number of rows per cob (NRPC), yield per plant (YPP; g), grain yield (GY;g) and total carotenoid contents (TCC; $\mu \mathrm{g} / \mathrm{g}$ ). Harvested cobs of all genotypes were kept in glasshouse to dry down to $14 \%$ moisture as different genotypes have different moisture contents at harvesting. Moisture percentage was estimated with the help of moisture meter (mini GAC ${ }^{\circledR}$ moisture tester). After equating the moisture contents, yield per genotype was measured. Total carotenoid contents (TCC) were also targeted for germplasm evaluation. TCC were determined spectrophotometrically using protocol described by Rodriguez-Amaya and Kimura, (2004). Reading was noted focusing spectrophotometric absorbance at $450 \mathrm{~nm}$. TCC were calculated using following formula Rodriguez-Amaya and Kimura (2004).

Total carotenoid contents $(\mu \mathrm{g} / \mathrm{g})=\frac{A_{(\text {total })} \times \text { volume }(\mathrm{ml}) \times 10^{4}}{A_{1 \mathrm{~cm}}^{1 \%} \times \text { Sample Weight }(\mathrm{g})}$

Whereas, $A_{(\text {total) }}$ : absorbance, volume: total volume of extract (25ml), $A_{1 \% \mathrm{~m}}^{1 \%}$ : absorption coefficient of 2500 .

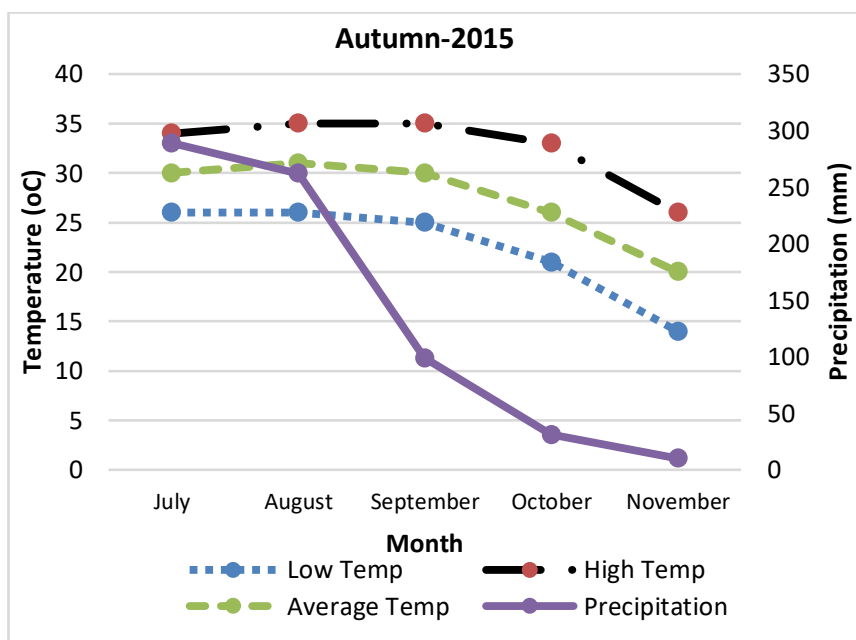

Figure 1.Temperature and precipitation record of research area during Autumn-2015.

Statistical analysis: Data of studied traits were analyzed for analysis of variance for augmented field design (Federer and Raghavarao, 1975). Data were subjected to summary statistics by using STAD-R Ver1.0 software (developed by Biometrics and Statistics Unit, CIMMYT). Correlation coefficients were estimated using Statistix9.1 Software. Dissection of correlation into direct and indirect effects was done by path coefficient analysis (Wright, 1921; Dewey and Lu, 1957). Principal component biplot was used for graphical display of genetic variability in yellow and white maize germplasm. Briefly principal component analysis (PCA) is multivariate analysis used for reduction of dimensionality in multivariate data and to transform the correlated variables into unassociated components. Objective of dimension reduction is obtained when few principal components (particularly $\mathrm{PC}_{1}$ and $\left.\mathrm{PC}_{2}\right)$ contribute most of variability $(70.00 \%-80.00 \%)$ in data (Everitt and Dunn, 1992; Gabriel, 1971). Biplot is 
graphical depiction of principal components using $\mathrm{X}$-axis and Y-axis (Everitt and Dunn, 1992; Gabriel, 1971).

\section{RESULTS}

Initially germplasm comprised of 175 white and 175 yellow genotypes at the time of sowing. Total 50 genotypes failed to produce productive cobs due to lack of germination, poor vigor, abnormal cob growth or due to miscellaneous losses. Among these non-productive genotypes, 25 belong to white germplasm and 25 belong to yellow maize germplasm. These 50 genotypes were eliminated from the data and further statistical inferences were made only on the basis of productive genotypes.

Blocking was proved effective measure as blocks were significantly different for all studied traits except stem lodging (Table 1). Entries (checks and tested genotypes) were significantly different for stem lodging, plant height, ear height, number of rows per cob, grains per row, days to $50 \%$ silking, days to $50 \%$ tasseling, anthesis silking interval, total carotenoid contents, yield per plant and grain yield. Genotypes used as local checks showed significant differences from other entries based on yield and its components except for root and stem lodging. Treatment genotypes were observed significantly different from other entries for all studied traits except root lodging. Genotypes grouped as treatment genotypes and check genotypes showed high level of differences among each other based on studied traits (Table 1).

Findings based on seed color explained that yellow genotypes were significantly different from each other for plant height, ear height, number of row per cob, grains per row, days to $50 \%$ silking, days to $50 \%$ tasseling, total carotenoid contents, yield per plant and grain yield. Whereas white genotypes were non-significantly different from each other for root lodging, total carotenoid contents and anthesis silking interval. Comparison between yellow and white genotypes exhibited significant differences based on all studied traits except root lodging (Table 1).

Standard error of difference between check means (SEd1), between any two means of test genotypes (SEd2), between any two entries of the same block (SEd3) and between means of test and check genotypes (SEd4) were given in Table 2 indicating different patterns of variation. Standard error of difference between check means (Sc), difference between adjusted yields of two selection means in the same block ( $\mathrm{Sb})$, difference between adjusted yields of two selection means in different blocks (Sv), difference between an adjusted

Table 1. Mean squares for yield and related components of maize genotypes.

\begin{tabular}{|c|c|c|c|c|c|c|c|c|c|c|c|c|c|}
\hline SOV & Df & $\mathbf{R L}$ & SL & PH & EH & DT & DS & ASI & NRPC & GPR & TCC & YPP & GY \\
\hline Blocks (B) & 6 & $12 * *$ & 0.18 & $20385 * *$ & $7184 * *$ & $39 * *$ & $99 * *$ & $6 * *$ & $23^{* *}$ & $2059 * *$ & $263 * *$ & $22304 * *$ & $1730768 * *$ \\
\hline Entries (E) & 353 & 2 & $0.47 * *$ & $4492 * *$ & $1210^{* * *}$ & $36 * *$ & $11 * *$ & $5^{*}$ & $29 * *$ & $196^{* * *}$ & $58 * *$ & $5417 * *$ & $1577452 * *$ \\
\hline Checks (C) & 3 & 3 & 0.09 & $711 * *$ & $761 * *$ & $31 * *$ & $35^{* *}$ & $6 * *$ & $15^{* *}$ & $15^{* *}$ & $56^{* *}$ & $14071^{* *}$ & $5628825^{* *}$ \\
\hline Varieties (V) & 349 & 2 & $0.47 * *$ & $4505 * *$ & $1207 * *$ & $37 * *$ & $11 * *$ & $6^{*}$ & $27 * *$ & $163^{* *}$ & $53 * *$ & $3835 * *$ & $211652^{*}$ \\
\hline Cvs V & 1 & $16^{* *}$ & $0.91 * *$ & $11261 * *$ & $3614 * *$ & 58 & $146 * *$ & $16^{* *}$ & $772 * *$ & $12208 * *$ & $1783 * *$ & $531563 * *$ & $466087556^{* *}$ \\
\hline Yellow (Y) & 174 & 2 & 0.17 & $4718 * *$ & $1191 * *$ & $39 * *$ & $12 * *$ & 3 & $26^{* *}$ & $182^{* *}$ & $55^{* *}$ & $5289 *$ & $236485^{*}$ \\
\hline White (W) & 174 & 2 & $0.69 * *$ & $4104 * *$ & $1177 * *$ & $34 * *$ & $9 * *$ & 2 & $25^{* *}$ & $137 * *$ & 0 & $2016^{*}$ & $178794^{*}$ \\
\hline Y vs W & 1 & 4 & $12 * *$ & $37190 * *$ & $9013 * *$ & $193 * *$ & $196 * *$ & $5 *$ & $682 * *$ & $1420 * *$ & $9027 * *$ & $71709 * *$ & $1607988 * *$ \\
\hline Error & 18 & 1 & 0.12 & 16 & 54 & 1.5 & 1 & 1 & 1 & 1 & 1 & 1113 & 109341 \\
\hline
\end{tabular}

Significance at $5 \%$ level of significance $=*$, Significance at $1 \%$ level of significance $=* *$, Where, RL: root lodging, SL: shoot lodging, PH: plant height $(\mathrm{cm}), \mathrm{EH}$ : ear height $(\mathrm{cm})$, NRPC: number of grain rows per cob, GPR: number of grains per row, DT: days to 50\% tasseling, DS: days to 50\% silking, ASI: anthesis silking interval, TCC: total carotenoid contents, YPP: yield per plant, GY: grain yield.

Table 2. Standard errors for various mean comparisons.

\begin{tabular}{|c|c|c|c|c|c|c|c|c|c|c|c|c|}
\hline & PH & EH & RL & SL & DT & DS & ASI & NRPC & GPR & YPP & GY & TCC \\
\hline SEd1 & 0.8 & 1.5 & 0.24 & 0.07 & 0.13 & 0.20 & 0.25 & 0.23 & 0.22 & 6.74 & 66.80 & 0.19 \\
\hline SEd2 & 5.6 & 10.4 & 1.68 & 0.49 & 0.93 & 1.42 & 1.73 & 1.58 & 1.52 & 47.19 & 467.63 & 1.32 \\
\hline SEd3 & 6.3 & 11.7 & 1.87 & 0.55 & 1.04 & 1.59 & 1.93 & 1.77 & 1.70 & 52.76 & 522.83 & 1.47 \\
\hline SEd4 & 4.7 & 8.8 & 1.42 & 0.42 & 0.79 & 1.20 & 1.46 & 1.34 & 1.29 & 39.88 & 395.22 & 1.12 \\
\hline $\mathrm{Sc}$ & 2.2 & 3.9 & 0.63 & 0.19 & 0.35 & 0.54 & 0.65 & 0.60 & 0.58 & 17.84 & 176.75 & 0.50 \\
\hline $\mathrm{Sb}$ & 5.6 & 10.4 & 1.68 & 0.50 & 0.93 & 1.42 & 1.73 & 1.58 & 1.52 & 47.19 & 467.63 & 1.32 \\
\hline $\mathrm{Sv}$ & 6.3 & 11.7 & 1.87 & 0.55 & 1.04 & 1.59 & 1.93 & 1.77 & 1.70 & 52.76 & 522.83 & 1.47 \\
\hline Svc & 4.7 & 8.8 & 1.42 & 0.42 & 0.79 & 1.20 & 1.46 & 1.34 & 1.29 & 39.88 & 395.22 & 1.11 \\
\hline LSI & 8.6 & 15.9 & 2.57 & 0.76 & 1.43 & 2.18 & 2.65 & 2.42 & 2.33 & 72.27 & 716.14 & 2.01 \\
\hline
\end{tabular}

Abbreviations: SEd1: standard error of difference between check means,SEd2: standard error of difference between any two means of test varieties (accessions), SEd3: standard error of difference between any two entries of the same block, SEd4: standard error of difference between means of test and check varieties, Sc: Difference between check means, Sb: Difference between adjusted yields of two selection means in the same block, Sv: Difference between adjusted yields of two selection means in different blocks, Svc: Difference between an adjusted selection yield and a check mean, LSI: leas significant increase 
selection yield and a check mean ( $\mathrm{Svc}$ ), least significant increase (LSI) were also estimated for between and within mean comparison of blocks, entries, checks and test genotypes (Table 2).

Summary statistics: Summary statistics including means, minimum value, maximum value and standard deviation for yellow and white genotypes was given in Table 3. Yellow genotypes have minimum 6 and maximum 22 number of rows per cob. Yellow genotypes had minimum 6 and maximum 52 grains per row whereas, white germplasm has 4 to 42 grains per row. Days to $50 \%$ tasseling and days to $50 \%$ silking were same for both types. Days to $50 \%$ tasseling ranged from 41 to
56 days. Maximum days to $50 \%$ silking were same in yellow and white genotypes (59.00 days after sowing). Anthesis silking interval (ASI) ranged from 0 to 6 days for white germplasm and -2 to 8 for yellow germplasm. Total carotenoid contents (TCC) were exclusively missing in white genotypes and yellow maize genotypes had 3.00 to $33.00 \mu \mathrm{g} / \mathrm{g}$ TCC. Highest yield per plant for yellow maize genotypes was $470.0 \mathrm{~g}$ and in case of white genotypes it was $283.0 \mathrm{~g}$. Minimum grain yield was same for both white and yellow germplasm $(6.0 \mathrm{~g})$ whereas, maximum yield for white genotypes was about $1900.0 \mathrm{~g}$ and for yellow genotypes was $2690.0 \mathrm{~g}$ (Table 3).

Table 3. Summary statistics for different traits of white and yellow maize.

\begin{tabular}{|c|c|c|c|c|c|c|c|c|c|c|c|c|}
\hline & \multicolumn{2}{|c|}{$\begin{array}{c}\text { Days to 50\% } \\
\text { silking }\end{array}$} & \multicolumn{2}{|c|}{$\begin{array}{c}\text { Days to 50\% } \\
\text { tasseling }\end{array}$} & \multicolumn{2}{|c|}{$\begin{array}{c}\text { Anthesis silking } \\
\text { interval }\end{array}$} & \multicolumn{2}{|c|}{ Plant height $(\mathrm{cm})$} & \multicolumn{2}{|c|}{ Ear height (cm) } & \multicolumn{2}{|c|}{ Root Lodging } \\
\hline & White & Yellow & White & Yellow & White & Yellow & White & Yellow & White & Yellow & White & Yellow \\
\hline Min & 44.00 & 43.00 & 41.00 & 41.00 & 0.00 & -2.00 & 45.00 & 66.00 & 20.00 & 25.00 & 0.00 & 0.00 \\
\hline Mean & 52.90 & 52.84 & 50.19 & 49.99 & 2.68 & 2.85 & 180.78 & 173.12 & 85.31 & 81.30 & 1.47 & 1.23 \\
\hline $\operatorname{Max}$ & 59.00 & 59.00 & 56.00 & 56.00 & 6.00 & 8.00 & 249.00 & 248.00 & 152.0 & 151.00 & 8.00 & 7.00 \\
\hline \multirow{2}{*}{$\begin{array}{l}\text { Standard } \\
\text { deviation }\end{array}$} & 3.44 & 3.24 & 3.62 & 3.13 & 1.40 & 1.57 & 31.11 & 36.55 & 23.24 & 24.64 & 1.46 & 1.40 \\
\hline & \multicolumn{2}{|c|}{ Shoot lodging } & \multicolumn{2}{|c|}{$\begin{array}{l}\text { Number of grain } \\
\text { rows per cob }\end{array}$} & \multicolumn{2}{|c|}{$\begin{array}{c}\text { Number of grains } \\
\text { per row }\end{array}$} & \multicolumn{2}{|c|}{$\begin{array}{c}\text { Total carotenoid } \\
\text { contents }\end{array}$} & \multicolumn{2}{|c|}{ Yield per plant } & \multicolumn{2}{|c|}{ Gield yield } \\
\hline Min & 0.00 & 0.00 & 4.00 & 6.00 & 4.00 & 6.00 & -- & 2.53 & 4.00 & 6.00 & 16.00 & 6.00 \\
\hline Mean & 0.66 & 0.30 & 11.50 & 12.81 & 17.65 & 22.12 & -- & 12.07 & 56.80 & 87.25 & 526.21 & 643.66 \\
\hline Max & 6.00 & 4.00 & 18.00 & 22.00 & 51.00 & 52.00 & -- & 32.67 & 270.00 & 470.00 & 1920.00 & 2690.0 \\
\hline $\begin{array}{l}\text { Standard } \\
\text { deviation }\end{array}$ & 1.10 & 0.60 & 2.53 & 2.47 & 10.14 & 11.77 & -- & 6.34 & 42.11 & 70.67 & 403.01 & 476.99 \\
\hline
\end{tabular}

Table 4. Correlation coefficients for yield and associated components for white and yellow maize genotypes.

\begin{tabular}{|c|c|c|c|c|c|c|c|c|c|c|c|c|}
\hline & Type & $\mathbf{R L}$ & SL & DT & DS & ASI & PH & EH & NRPC & GPR & YPP & GY \\
\hline \multirow[t]{2}{*}{ RL } & White & 1.00 & & & & & & & & & & \\
\hline & Yellow & 1.00 & & & & & & & & & & \\
\hline \multirow[t]{2}{*}{ SL } & White & -0.03 & 1.00 & & & & & & & & & \\
\hline & Yellow & 0.01 & 1.00 & & & & & & & & & \\
\hline \multirow[t]{2}{*}{ DT } & White & $-0.15^{*}$ & $0.23^{* *}$ & 1.00 & & & & & & & & \\
\hline & Yellow & -0.03 & -0.09 & 1.00 & & & & & & & & \\
\hline \multirow[t]{2}{*}{ DS } & White & $-0.21 * *$ & $0.20^{* *}$ & $0.93 * *$ & 1.00 & & & & & & & \\
\hline & Yellow & 0.02 & -0.08 & $0.88^{* *}$ & 1.00 & & & & & & & \\
\hline \multirow[t]{2}{*}{ ASI } & White & -0.12 & -0.11 & $-0.32 * *$ & 0.06 & 1.00 & & & & & & \\
\hline & Yellow & 0.10 & 0.00 & $-0.18 * *$ & $0.31 * *$ & 1.00 & & & & & & \\
\hline \multirow[t]{2}{*}{ PH } & White & -0.15 & $0.36^{* *}$ & 0.02 & 0.03 & 0.03 & 1.00 & & & & & \\
\hline & Yellow & 0.13 & 0.08 & -0.09 & -0.05 & 0.08 & 1.00 & & & & & \\
\hline \multirow[t]{2}{*}{$\mathrm{EH}$} & White & -0.09 & $0.39 * *$ & 0.07 & 0.04 & -0.08 & $0.76^{* *}$ & 1.00 & & & & \\
\hline & Yellow & $0.21^{* *}$ & 0.09 & -0.06 & 00.00 & 0.12 & $0.82 * *$ & 1.00 & & & & \\
\hline \multirow[t]{2}{*}{ NRPC } & White & -0.05 & $-0.18 * *$ & -0.01 & -0.01 & 0.00 & $0.18^{* *}$ & 0.13 & 1.00 & & & \\
\hline & Yellow & -0.08 & $-0.22 * *$ & -0.06 & -0.06 & 0.00 & -0.07 & -0.13 & 1.00 & & & \\
\hline \multirow[t]{2}{*}{ GPR } & White & 0.00 & $0.17 * *$ & -0.03 & -0.03 & 0.00 & $0.14 * *$ & 0.08 & 0.02 & 1.00 & & \\
\hline & Yellow & -0.20 ** & 0.04 & $-0.16^{*}$ & -0.14 & -0.03 & $0.20^{* *}$ & 0.06 & $0.23 * *$ & 1.00 & & \\
\hline \multirow[t]{2}{*}{ YPP } & White & -0.16 & -0.03 & 0.06 & 0.06 & 0.00 & 0.03 & 0.05 & 0.07 & $0.47 * *$ & 1.00 & \\
\hline & Yellow & $-0.23 * *$ & -0.06 & -0.07 & -0.09 & 0.04 & 0.00 & -0.10 & $0.25 * *$ & $0.39 * *$ & 1.00 & \\
\hline \multirow[t]{2}{*}{ GY } & White & -0.03 & $0.27 * *$ & 0.06 & 0.05 & -0.04 & $0.41 * *$ & $0.46^{* *}$ & $0.15^{*}$ & $0.52 * *$ & $0.59 * *$ & \\
\hline & Yellow & -0.06 & -0.04 & -0.10 & -0.14 & 0.08 & $0.43^{* *}$ & $0.35^{* *}$ & $0.23 * *$ & $0.49^{* *}$ & $0.58 * *$ & \\
\hline \multirow[t]{2}{*}{ TCC } & White & -- & -- & -- & -- & -- & -- & -- & -- & -- & -- & -- \\
\hline & Yellow & 0.00 & -0.12 & 0.08 & 0.10 & -0.02 & $-0.23 * *$ & $-0.21 * *$ & $0.21 * *$ & -0.08 & $0.21 *$ & -0.02 \\
\hline
\end{tabular}

Where, RL: root lodging, SL: shoot lodging, PH: plant height $(\mathrm{cm})$, EH: ear height $(\mathrm{cm})$, NRPC: number of grain rows per cob, GPR: number of grains per row, DT: days to $50 \%$ tasseling, DS: days to 50\% silking, ASI: anthesis silking interval, TCC: total carotenoid contents, YPP: yield per plant, GY: grain yield. 
Correlation Coefficient Analysis:

White maize germplasm: Correlation coefficients were estimated to access the association of subjected traits and to define most appropriate selection criteria. Correlation analysis was carried out separately for yellow and white germplasm. Days to $50 \%$ silking had strong positive correlation with days to $50 \%$ tasseling. Plant height showed strong positive correlation with ear height. Yield per plant exhibited highly stronger positive correlation with grains per row rather than number of rows per cob. Grain yield has highly positive correlation with plant height, ear height, number of rows per cob, grains per row and yield per plant (Table 4). Absence of correlation between days to 50\% silking and days to 50\% tasseling with grain yield (Table 4) showed that vegetative growth period is least decisive for defining yield potential and presumed that post-pollination growth stages were more effective for defining the yield potential.

Yellow maize germplasm: ASI has positive correlation with days to $50 \%$ silking. Ear height was positively correlated with plant height. Number of rows per cob was positively correlated with yield per plant, grains per row and total carotenoid contents. Days to 50\% silking and days to $50 \%$ tasseling have strong positive correlation. Total carotenoid contents were positively correlated with yield per plant but had no correlation with grain yield which showed that total carotenoid contents were independent of grain yield. Yield per plant was positively correlated with grains per row. Grain yield was positively correlated with ear height, plant height, number of rows per cob, yield per plant and grains per row. Days to $50 \%$ tasseling and days to $50 \%$ silking were negatively correlated with grains per row and grain yield (Table 4).

Path coefficient analysis: Correlation coefficients were partitioned into their direct and indirect effects for further exploration of linkage of yield with other components. All the traits under study showed direct effects on the yield either positively or negatively.

White germplasm: Days to 50\% tasseling and ASI had highly negative direct effect on grain yield. Days to 50\% silking exerted highly positive direct effects on grain yield. Days to $50 \%$ tasseling had positive indirect effect on yield via ASI. Grains per row showed indirect positive effect on yield via yield per plant (Fig. 2).

Yellow germplasm: ASI, days to $50 \%$ tasseling, yield per plant and grains per row exerted positive direct effect on yield. Days to $50 \%$ silking posed highly negative direct effect on the yield of yellow maize germplasm. Days to 50\% silking exerted positive indirect effect on yield via grains per row. Yield per plant showed highly positive indirect effect on the yield through grains per row (Fig. 3).

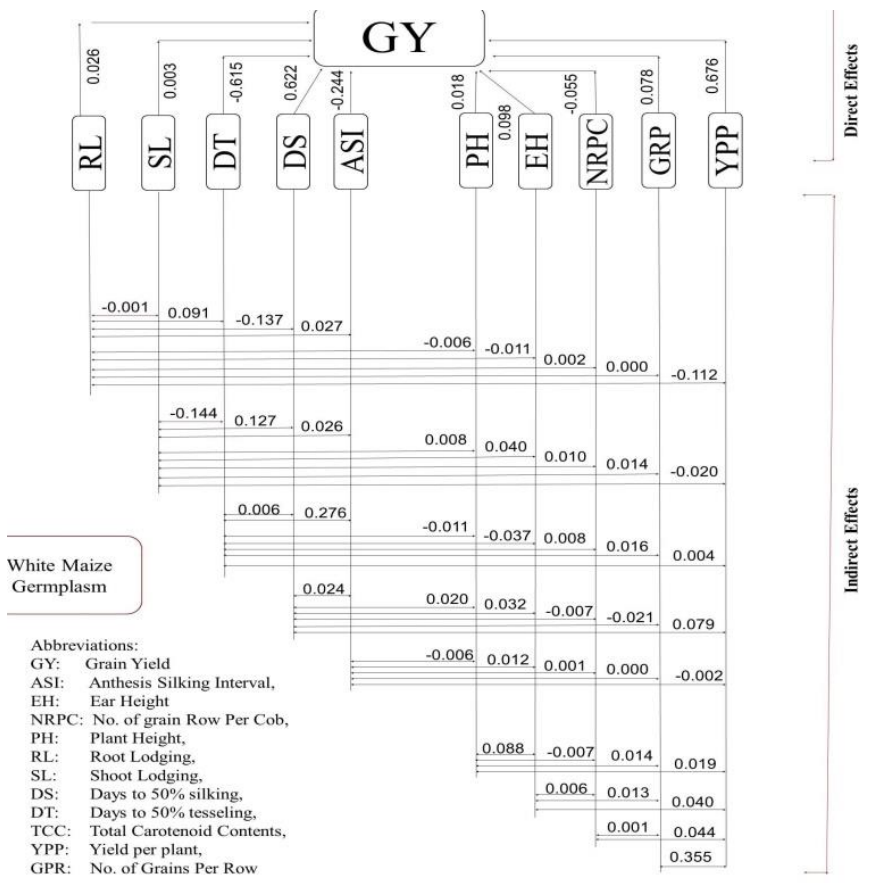

Figure 2.Path diagram showing direct and indirect effects of different yield components on yield of white maize germplasm.

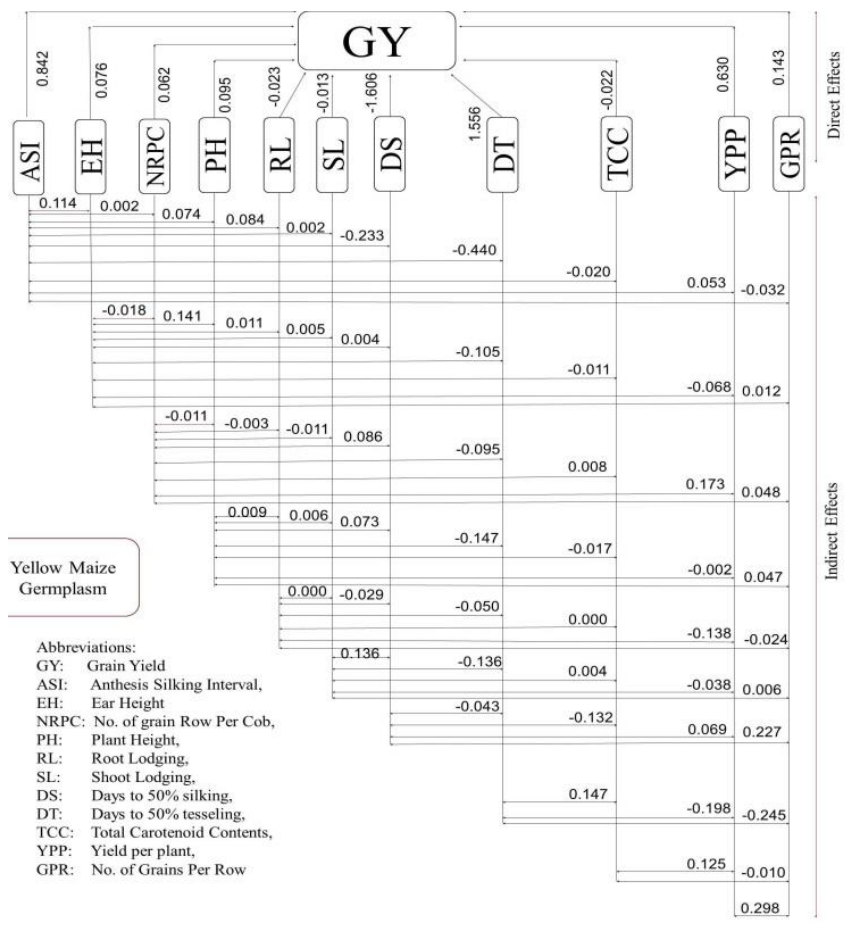

Figure 3.Path diagram showing direct and indirect effects of different yield components on yield of yellow maize germplasm. 
Principal component biplot: Principal component biplots were developed for white and yellow maize germplasm separately to figure out the genetic variability in respective germplasm. Genotypes scattered across the origin of graph were having average performance for subjected traits. Genotypes dispersed away from origin in the direction of the vector arrow were indicators of having higher mean values whereas genotypes located far from origin opposite to arrow were having poor performance for subjected traits. PCA biplot graph for white maize germplasm is depicting the 90.72\% (PC-1: $55.61 \%$ and PC-2: $35.11 \%$ ) of total genetic variability in raw data. Names of genotypes are mentioned according to the accession numbers allotted by Plant Genetic Resource Institute (PGRI), NARC, Islamabad, Pakistan. Accession numbers were given in parenthesis. Among white maize genotypes, 142 (19189), 86 (15159), 149 (19201), 25 (15018), 89 (15216), 87 (15170), 83 (15155), 147 (19196), 116 (15318), 131 (19174), 97 (15263), 113 (15284), 93 (15227), 120 (15327), 130 (15355), 64 (15125) and 112 (15282) showed superior performance for subjected yield components. Whereas, genotypes 96 (15260), 54 (15092), 46 (15063), 110 (15280), 143 (19190), 70 (15137), 2 (14976), 12 (24680) and 42 (15051) performed poorly (lower mean values) for subjected traits among white maize germplasm (Fig 4).

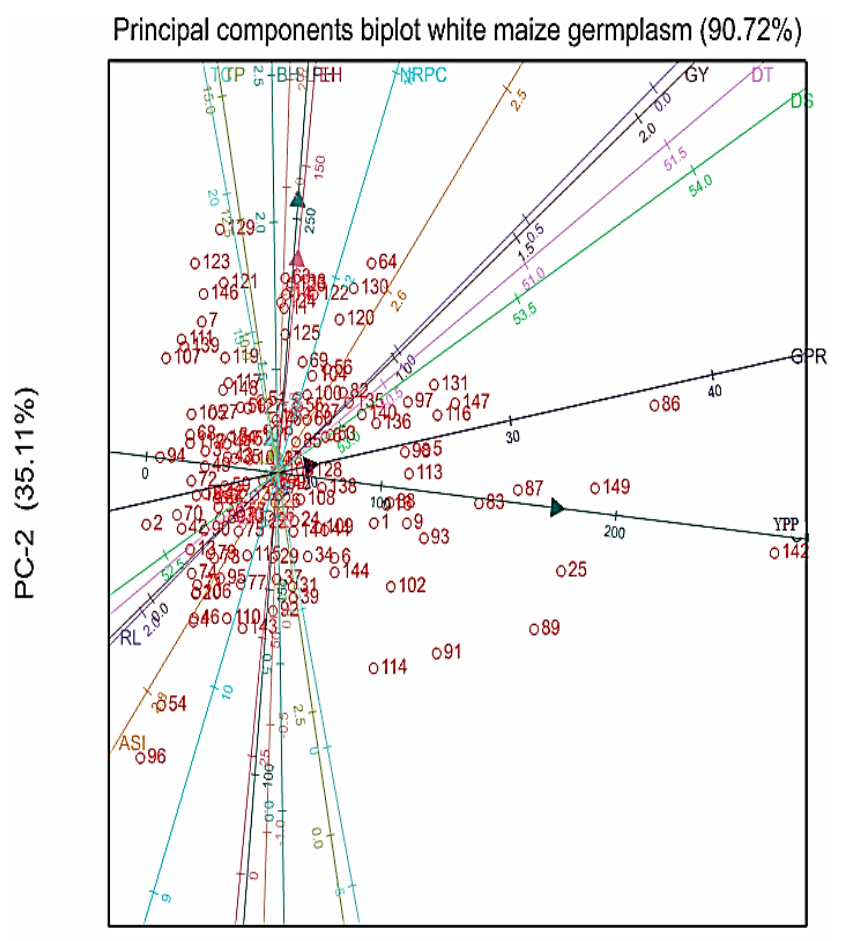

PC-1 (55.61\%)

Figure 4.Principal component biplot for white maize germplasm.
PCA biplot results for yellow maize germplasm represented 95.11\% (PC-1: $70.27 \%$ and PC-2: $24.84 \%$ ) of total variability in raw data. Among yellow maize genotypes, 3 (14965), 15 (14982), 148 (19205), 43 (15019), 8 (14971), 93 (15163), 112 (15205), 27 (24687), 113 (15207), 110 (15194), 107 (15190), 96 (15169), 99 (15173), 98 (15172), 105 (15187), 103 (15185), 117 (15226), 97 (15171), 73 (15105), 141 (19175), 142 (19178), 52 (15061), 23 (24679), 83 (15128) and 140 (15353) were better performers for subjected yield components. However, genotypes 41 (15011), 33 (14882), 59 (15075), 55 (15068), 54 (15067), 132 (15322), 146 (19197), 4 (14966), 90 (15153), 37 (14917), 9 (14972), 10 (14973), 118 (15229) and 19 (14990) were proved poor performers among yellow maize germplasm based on subjected yield components (Fig 5).

Principal components biplot for yellow maize germplasm (95.11\%)

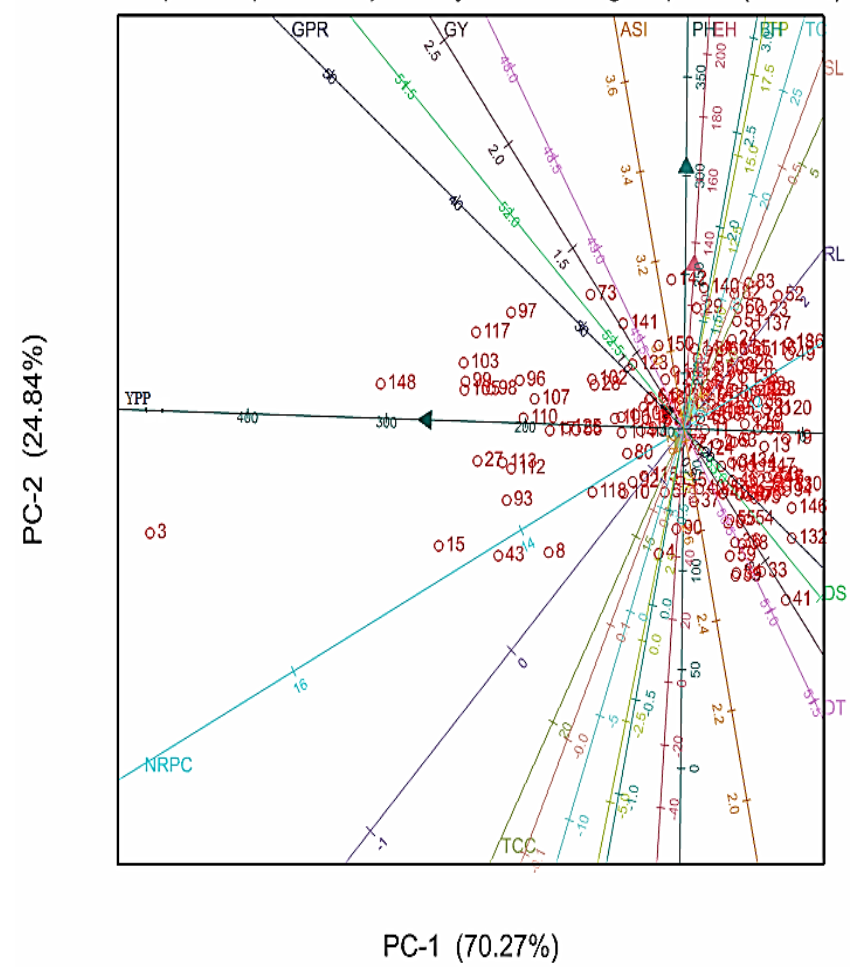

Figure 5.Principal component biplot for yellow maize germplasm.

\section{DISCUSSION}

Comparison of yield potential: Presence of genetic variability in any available germplasm at allelic level is a basic prerequisite for genetic improvement. Available information about nature and magnitude of genetic variability guide the breeders to chalk out breeding programs for genetic improvement. Evaluation of maize germplasm under augmented design revealed the significant differences among accessions for the subjected yield and yield components. 
Entries, checks and tested genotypes were significantly different for all of the studied traits except root lodging. Entries include checks and tested varieties. Contrast analysis between checks and tested varieties showed the significant differences among tested varieties comprised of both yellow and white genotypes. Contrasts were generated for comparison of yellow and white germplasm which showed that yellow and white germplasm were significantly different from each other. Nzuve et al. (2014) and Shakoor et al. (2007) also reported the significant genetic variability in tropical maize germplasm for yield and yield components.

Summary statistics showed that yield per plant and grain yield of the yellow genotypes was higher than white genotypes. Higher yield of yellow maize germplasm is attributed to more number of grains per row and number of grain rows per cob. It was reported in literature that higher yield of the yellow maize genotypes may be associated with higher input application and more sophisticated management practices (Mejia and Peel, 2009). However, in current study, both white and yellow maize genotypes were subjected to the same level of inputs, management practices and nutrient supplements. Therefore, higher yield of yellow maize genotypes showed that yellow germplasm has higher yield potential. For combating the food security problem, provitamin A malnutrition, and fulfilling the requirements of exploding poultry industry in the country there is dire need to promote the cultivation of the yellow maize (de Almeida Rios et al., 2014). White germplasm has also its worth and scope as being the raw material for dry milling industry (Mejia and Peel, 2009). It could be inferred that industrial sector should manage the cultivation of white maize whereas, for general public health, nutritional quality, food security, poultry industry and other associated sectors cultivation of yellow maize germplasm should be promoted.

Selection criteria: A selection criterion is defined, based on the correlation of yield with different yield components. Correlation coefficients of the yellow and white maize germplasm were estimated separately to facilitate the mapping of selection criteria. Rapid genetic improvement of maize germplasm was attained through correlation assisted selection (Ogunniyan and Olakojo, 2014). Grain yield in the white maize germplasm is positively correlated with plant height, ear height, grains per row, number of rows per cob and yield per plant. Therefore, genetic improvement in yield potential of white maize genotypes was direly dependent on the genetic improvement of yield per plant, grains per row, ear height, plant height and number of rows per cob.

In yellow maize germplasm, grain yield is positively correlated with plant height, ear height, number of rows per cob, yield per plant and grains per row. Moderate negative correlation between grain yield, days to $50 \%$ silking and days to $50 \%$ tasseling is also observed for yellow maize genotypes. However, this correlation was insignificant based on the probability values thus, these were not actual correlations.
Ogunniyan and Olakojo (2014) reported the positive correlation of grain yield with anthesis silking interval whereas, in current experiment these traits were independent of each other and these differences may be attributed to different genetic basis of the germplasm. Total carotenoid contents were absent in white maize germplasm whereas, in yellow maize germplasm, grain yield was independent of the total carotenoid contents. Higher or lower total carotenoid contents have no effect on the grain yield. As correlation pattern of yield components with yield was similar for yellow and white maize germplasm thus, selection criteria for genetic improvement of yield could also be similar for both type of genotypes. Similar type of correlation was also reported by other researchers irrespective of the nature of germplasm either yellow or white (Yousuf et al., 2001; Rafique et al., 2004). Previously it was reported that yield and provitamin A carotenoids contents have no correlation (Menkir et al., 2014; Suwarno et al., 2014; Dhliwayo et al., 2014) and, similar results were also found in current study. It may be concluded that total carotenoid contents and yield in yellow maize germplasm could be improved simultaneously.

Sometimes correlation coefficients between two variables are due to the indirect effects of the third variable. Yield components which have highly positive correlation and direct effects on the yield are most appropriate to be used as selection criteria for genetic improvement (Dewey and Lu 1957; Pavan et al., 2011). For white germplasm, yield per plant have high direct effects on the grain yield. Yield per plant have higher positive correlation and directs effects on the yield thus, these are most appropriate traits to be used as selection criteria for genetic improvement of white germplasm. In yellow maize germplasm, anthesis silking interval, days to 50\% tasseling, yield per plant and grains per row have high direct effects on the yield. In yellow maize germplasm, yield per plant and grains per row have significant strong positive correlation and direct effects on the yield. Therefore, for yellow maize germplasm, yield per plant and grains per row were the most appropriate traits to be used as selection criteria for genetic improvement of yield. Shakoor et al. (2007) also dissected the correlation coefficients and found that number plant height and ear height have desirable effects on the maize yield.

Potential candidate genotypes: PCA is one of the multivariate analyses, and extensive reports are available for use of PCA biplots for evaluation of variability in different type of crop species (Aslam et al., 2013; Aslam et al., 2014; Ashraf et al., 2015; Latif et al., 2015; Mustafa et al., 2015). Based on the results of PCA biplot best performing genotypes were selected from the white and yellow maize germplasm. Among white genotypes, 19189, 15159, 19201, 15018, $15216,15170,15155,19196,15318,19174,15263,15284$, $15227,15327,15355,15125$ and 15282 genotypes were promising based on studied yield and related components. Among yellow maize germplasm, 14965, 14982, 19205, 
$15019,14971,15163,15205,24687,15207,15194,15190$, $15169,15173,15172,15187,15185,15226,15171,15105$, $19175,19178,15061,24679,15128$ and 15353 were the best genotypes based on yield, related components and total carotenoid contents.

Conclusions: It may be concluded from current study that maize germplasm in Pakistan has significant genetic variability for yield and yield components. This genetic variability is the source of raw material for further genetic improvement of maize germplasm. Both white and yellow types are having significant within and between genetic variability for yield and yield components. Yield of the yellow maize genotypes is higher than white genotypes which is attributed to more grains per row and more number of rows per cob. Different yield components have different magnitude and direction of correlation with yield in white and yellow maize germplasm. Based on the coefficients of correlation and path analysis, yield per plant is key target trait for genetic improvement for white genotypes whereas, yield per plant and grains per row are most appropriate traits for yellow maize germplasm. PCA biplot also facilitated the selection of best performing genotype among yellow and white germplasm which could be used as parental material in different breeding programs. So far as future prospects are concerned, with due prevalence of provitamin A malnutrition across the country, there is also need to evaluate the yellow maize germplasm for estimating the variability of provitamin A carotenoids. Provitamin A biofortified maize genotypes are the key breeding prospects for maize in Pakistan.

Acknowledgement: Authors acknowledge HEC, Pakistan for provision of funds for this study and Dr. Saddar Uddin Siddique, Principal Scientific Officer, Plant Genetic Resource Institute (PGRI), NARC, Islamabad, Pakistan for provision of maize germplasm used in current study.

\section{REFERENCES}

Abbas, M., A. Bakhsh, M. Aleem, M. Ashraf, M.B. Idrees and N.A. Buttar. 2017. Maize productivity analysis under drip irrigation and bed planting. J. Glob. Innov. Agric. Soc. Sci.5:32-38.

Ashraf, A., A. El-Mohsen, M.A. Abd El-Shafi, E.M.S. Gheith and H.S. Suleiman. 2015. Using different statistical procedures for evaluating drought tolerance indices of bread wheat genotypes. Adv. Agric. Biol. 4:19-30.

Aslam, M., K. Ahmad, M.A. Maqbool, S. Bano, Q.U. Zaman and G.M. Talha. 2014. Assessment of adaptability in genetically diverse chickpea genotypes (Cicer arietinum L.) based on different physio-morphological standards under ascochyta blight inoculation. Int. J. Adv. Res. 2:245-255.
Aslam, M., M.A. Maqbool, S. Akhtar and W. Faisal. 2013. Estimation of genetic variability and association among different physiological traits related to biotic stress (Fusarium oxysporum L.) in chickpea. J. Anim. Plant Sci. 23:1679-1685.

Badu-Apraku, B., A. Menkir, S. Ajala, R. Akinwale, M. Oyekunle and K. Obeng-Antwi. 2010. Performance of tropical early-maturing maize cultivars in multiple stress environments. Can. J. Plant Sci. 90: 831-852.

Badu-Apraku, B. and R.O. Akinwale. 2011. Identification of early-maturing maize inbred lines based on multiple traits under drought and low $\mathrm{N}$ environments for hybrid development and population improvement. Can. J. Plant Sci. 91:931-942.

Brown, W.L., M.S. Zuber, L.L. Darrah and D.V. Glover. 1985. Origin, adaptation, and types of corn. Cooperative Extension Service Iowa State University Ames, Iowa 50011.

de Almeida Rios, S ., M.C.D. Paes, W.S. Cardoso, A. Borém and F.F. Teixeira. 2014. Color of corn grains and carotenoid profile of importance for human health. Amer. J. Plant Sci. 5:857-862.

Dewey, D.R. and K.H. Lu. 1959. A correlation and path coefficient analysis of component of crested wheat grass seed production. Agron. J. 51:515-518.

Dhawan, N.L. 1964. Primitive maize in Sikkim. Maize Genetics Coop. Newslett. 38: 69-70.

Dhliwayo, T., N. Palacios-Rojas, J. Crossa and K.V. Pixley. 2014. Effects of S1 recurrent selection for provitamin A Carotenoid content for three open-pollinated maize cultivars. Crop Sci. 54:2449-2460.

Erenstein, O. 2010. The evolving maize sector in Asia: Challenges and opportunities. J. New Seeds. 11:1-15.

Everitt, B.S. and G. Dunn. 1992. Applied multivariate data analysis. Oxford University Press, New York, NY.

Federer, W.T. and D. Raghavarao. 1975. On augmented designs. Biometrics 31:29-35.

Gabriel, K.R. 1971. The biplot graphic display of matrices with application to principal component analysis. Biometrka 58:453-467.

Latif, A., M. Bilal, S.B. Hussain and F. Ahmad. 2015. Estimation of genetic divergence, association, direct and indirect effects of yield with other attributes in cotton (Gossypium hirsutum L.) using biplot correlation and path coefficient analysis. Trop. Plant Res. 2:120-126.

Mejia, M. and D.S. Peel. 2009. White corn and yellow corn production in Mexico: Food versus Feed. Analysis \& Comments Livestock Marketing Information Center State Extension Services in Cooperation with USDA.

Menkir, A. and B. Maziya-Dixon. 2004. Influence of genotype and environment on b-carotene content of tropical yellow-endosperm maize genotypes. Maydica 49:313-318. 
Mustafa, H.S.B., J. Farooq, E. Hasan, T. Bibi and T. Mahmood. 2015. Cluster and principle component analyses of maize accessions under normal and water stress conditions. J. Agric. Sci. 60:33-48.

Muzhingi, T., A. Langyintuo, L. Malaba and M. Banzinger. 2008. Consumer acceptability of yellow maize products in Zimbabwe. Food Policy 33:352-361.

Nzuve, F., S. Githiri, D.M. Mukunya and J. Gethi. 2014. Genetic variability and correlation studies of grain yield and related agronomic traits in maize. J. Agric. Sci. 6:166-176.

Ogunniyan, D.J. and S.A. Olakojo. 2014. Genetic variation, heritability, genetic advance and agronomic character association of yellow elite inbred lines of maize (Zea mays L.). Niger. J. Gen. 28:24-28.

Pavan, R., H.C. Lohithaswa, M.C. Wali, G. Prakash and B.G. Shekara. 2011. Correlation and path coefficient analysis of grain yield and yield contributing traits in single cross hybrids of maize (Zea mays L.). Electronic J. Plant Breed. 2:253-257.

Pritchett, J. and L. Li. 2002. Price risk management in white corn production. Presented at the 2002 Western Agricultural Economics Association Annual Meetings Long Beach, CA.

Rafique, M., A. Hussain, T. Mahmood, A.W. Alvi and M.B. Alvi. 2004. Heritability and interrelationships among grain yield and yield components in maize (Zea mays L). Int. J. Agric. Biol. 6:1113-1114.
Rodriguez-Amaya, B.D. and M. Kimura. 2004. HarvestPlus Hand-book for Carotenoid Analysis. HarvestPlus Technical Mono-graph 2, Washington, DC and Cali: International Food Policy Research Institute (IFPRI) and International Center for Tropical Agriculture (CIAT). Available online at http://www.harvestplus.org/sites/default/files/tech02.pdf

Shakoor, M.S., M. Akbar and A. Hussain. 2007. Correlation and path coefficients studies of some morphophysiological traits in maize double crosses. Pak. J. Agri. Sci. 44: 213-216.

Suwarno, W.B., K.V. Pixley, N. Palacios-Rojas, S.M. Kaeppler and R. Babu. 2014. Formation of heterotic groups and understanding genetic effects in a provitamin A biofortified maize breeding program. Crop Sci. 54:14 $-24$.

USDA-FAS. 2008. Production, supply and distribution (PS\&D) database. Available online at http:// www.fas.usda.gov/psdonline/

Wright, S. 1921. Correlation and causation. J. Agric. Res. 20:557-585.

Yousuf, M. and M. Saleem. 2001. Correlation analysis of $S_{1}$ families of maize for grain yield and its components. Int. J. Agric. Biol. 4:387-388.

Zulfiqar, U., M.U. Yasin, M. Ishfaq, N. Ali., S. Durrani, T. Ahmad and H.S. Saeed. 2017. Influence of foliar application of zinc on yield of maize (Zea mays L.) under water stress at different stages. J. Glob. Innov. Agric. Soc. Sci. 5:165-169. 